\title{
SELEÇÃO DE PRIMERS INTER SIMPLE SEQUENCE REPEAT EM Melocactus conoideus BUIN. \& BRED. (CACTACEAE), ESPÉCIE ENDÊMICA DO SUDOESTE DA BAHIA, BRASIL
}

Anderson Carvalho Vieira ${ }^{1}$, Tarcísio dos Santos Cardoso², Thalana Souza Santos Silva ${ }^{3}$, Carlos Bernard Moreno Cerqueira-Silva ${ }^{1,2,3}$, Elisa Susilene Lisboa dos Santos ${ }^{1,2,3^{*}}$

${ }^{1}$ Programa de Pós-graduação em Ciências Ambientais, Universidade Estadual do Sudoeste da Bahia.

${ }^{2}$ Departamento de Ciências Exatas e Naturais, Universidade Estadual do Sudoeste da Bahia.

${ }^{3}$ Programa Multicêntrico em Bioquímica e Biologia Molecular, Universidade Estadual do Sudoeste da Bahia *Autora de Correspondência (elisa.lisboa@uesb.edu.br)

Recebido em: 06/04/2019 - Aprovado em: 10/06/2019 - Publicado em: 30/06/2019 DOI: 10.18677/EnciBio_2019A122

\section{RESUMO}

O Melocactus conoideus é uma espécie listada como criticamente ameaçada de extinção, o que evidencia a necessidade de ações de pesquisa que contribuam para a sua proteção. No entanto, são poucos os estudos acerca da espécie em diversos aspectos, sobretudo os embasados em informações genéticas com o uso de marcadores moleculares. Nesse contexto, o presente trabalho teve como objetivo caracterizar o perfil de segmentos de DNA amplificados e selecionar primers Inter Simple Sequence Repeat (ISSR) visando subsidiar análises genéticas em $M$. conoideus. Quatro genótipos da espécie foram utilizados para a análise molecular com 23 primers ISSR. Foram observadas 118 marcas (40,7\% polimórficas) com média de 7,87 marcadores por iniciador. Com base no padrão de geração de marcas, 15 primers se mostraram adequados, exibindo de 4 a 11 marcadores com boa qualidade de visualização. A heterozigosidade esperada e o Conteúdo de Informação Polimórfica também foram estimados, exibindo valores médios de 0,43 e 0,33 , respectivamente. Estes marcadores possuem potencial uso em estudos moleculares em $M$. conoideus incluindo estimativas de variabilidade e estruturação genética visando conhecer a base genética da espécie e auxiliar no manejo para a conservação.

PALAVRAS-CHAVE: Cabeça-De-Frade; Espécie Criticamente Ameaçada; Marcadores Moleculares.

\section{SELECTION OF INTER SIMPLE SEQUENCE REPEAT PRIMERS IN Melocactus conoideus BUIN. \& BRED. (CACTACEAE), ENDEMIC SPECIES OF SOUTHWEST BAHIA, BRAZIL}

\section{ABSTRACT}

Melocactus conoideus is a species listed as critically endangered, which evidences the need for research actions that contribute to its protection. However, there are few studies about the species in several aspects, mainly genetic information from of 
molecular markers. In this context, the present work aimed to characterize the profile of amplified DNA segments and to select Inter Simple Sequence Repeat (ISSR) primers to support genetic analysis in $M$. conoideus. Four genotypes of the species were used for molecular analysis with 23 ISSR primers. A total of 118 markers (40.7\% polymorphic) were observed and a mean of 7.87 markers per primer. Based on the pattern of brand generation, 15 primers appeared adequate, displaying from 4 to 11 markers with good quality of visualization. The means of the expected heterozygosity and polymorphic information content were 0.43 and 0.33 , respectively. These markers have potential use in genetic-molecular studies in $M$. conoideus including genetic variability and structure in order to know the genetic basis and to aid e in the conservation strategies.

KEYWORDS: Cabeça-De-Frade; Critically Endangered Species; Molecular Markers.

\section{INTRODUÇÃO}

O gênero Melocactus Link \& Otto (família Cactaceae) possui cerca de 38 espécies distribuídas pela América Central e do Sul, comuns em zonas áridas e semiáridas, e apesar da ampla distribuição é um grupo marcado por endemismos (RIZZINI, 1982; TAYLOR, 1991; CORREIA et al., 2018). No Brasil, atualmente 23 espécies são encontradas na região leste do país, ocorrendo nos estados do Amazonas, Roraima, Piauí, Rio Grande do Norte, Ceará, Paraíba, Pernambuco, Bahia, Minas Gerais, Espírito Santo e Rio de Janeiro (ZAPPI et al., 2018). O estado da Bahia contém a maior diversidade e número de espécies endêmicas do gênero; das 19 espécies que ocorrem no estado, 10 são endêmicas e sete classificadas dentro das diferentes categorias de risco da lista vermelha da International Union for Conservation of Nature (IUCN) (CORREIA et al., 2018; ZAPPI et al., 2018).

Dentre as espécies ocorrentes na Bahia, destaca-se o Melocactus conoideus Buin. \& Bred conhecido popularmente como "cabeça-de-frade-do-Periperi" (RIZZINI, 1982; TAYLOR, 1992; CERQUEIRA-SILVA; SANTOS, 2008). A espécie ocorre em manchas de vegetação com solo rico em cascalho de quartzo, dentro dos limites da mesorregião do município de Vitória da Conquista - BA. M. conoideus é classificado como criticamente ameaçado na lista vermelha da IUNC, devido ao histórico de pressão antrópica envolvendo a comercialização ilegal da espécie para fins ornamentais em mercado nacional e internacional e a fragmentação ambiental gerada a partir da urbanização irregular (TAYLOR, 1992; CERQUEIRA-SILVA; SANTOS, 2008; MACHADO et al., 2013; LUZ-FREIRE et al., 2014).

Para a conservação e manutenção populacional de $M$. conoideus, medidas contra a comercialização ilegal foram criadas pela International Trade in Endangered Species of Wild Fauna and Flora (CITES), além da destinação de uma área específica dentro da Unidade de Conservação do Parque Municipal da Serra do Periperi (TAYLOR, 1992; MACHADO et al., 2013). Na Reserva Ambiental do Melocactus conoideus são realizados estudos associados ao conhecimento ecológico da espécie (CERQUEIRA-SILVA; SANTOS, 2008; MACHADO et al., 2013). Também é realizada a produção de mudas no Herbário Sertão da Ressaca, com a finalidade de aumento populacional de $M$. conoideus dentro da área da reserva (PMVC, 2016; PMVC, 2017).

Em detrimento ao status de ameaça do $M$. conoideus, ainda é relativamente baixa a produção científica acerca da espécie em diversos aspectos, o que impossibilita o desenvolvimento de ações de proteção e manejo efetivas. Nesse sentido, as análises genético-moleculares podem auxiliar no acesso a informações 
acerca da base genética da espécie, contribuindo para a compreensão do status de variabilidade genética bem como das interações ecológicas relacionadas aos aspectos reprodutivos que influenciam na sobrevivência de populações em ambiente natural, indispensáveis para o sucesso em ações de programas de proteção de espécies (FARJADO et al., 2016).

Uma importante ferramenta para se adquirir dados em nível de DNA são os marcadores moleculares. Dentre os marcadores baseados na PCR (Polymerase Chain Reaction) está o ISSR (Inter Simple Sequence Repeats), que explora regiões repetitivas (microssatélites) distribuídas aleatoriamente ao longo do genoma (TURCHETTO-ZOLET et al., 2017). A técnica utiliza um único iniciador (primer) possuindo entre 16 a 25 pares de bases (pb), que se ancora nas regiões repetitivas, amplificando regiões inter-SSR, geralmente entre 200 a 2000 pb (REDDY et al., 2002). Tais marcadores são amplamente usados em análises genéticas relacionados à identificação, classificação e quantificação da variabilidade genética de espécies silvestres de interesse ecológico, graças ao seu nível de reprodutibilidade, além de não exigirem o conhecimento prévio do genoma para sua aplicação (REDDY et al., 2002).

Um estágio que antecede o início de análises baseadas em marcação molecular é a descrição do perfil de marcação e seleção de primers adequados, sendo uma fase preliminar de triagem daqueles que possuam a melhor visualização dos amplicons, reprodutibilidade e existência de polimorfismo, subsidiando informações cruciais para os resultados posteriores em estudos de genética populacional (COSTA et al., 2015; MATOS-OLIVEIRA, et al., 2018; SILVA et al., 2018). Diante deste contexto, o presente trabalho teve como objetivo caracterizar o perfil de geração de marcadores e selecionar primers ISSR adequados para emprego em análises moleculares em Melocactus conoideus.

\section{MATERIAL E MÉTODOS}

As análises foram desenvolvidas no Laboratório de Genética Molecular Aplicada (LGMA) localizado na Universidade Estadual do Sudoeste da Bahia (UESB) campus Juvino Oliveira, Itapetinga, Bahia. Foi usado como fonte de DNA genômico de $M$. conoideus frutos coletados de quatro espécimes oriundas da Reserva Ambiental do Melocactus conoideus, dentro do Parque Municipal Serra do Periperi (1449'49"S; 4050'0.3"W), em Vitória da Conquista - Bahia. O DNA foi obtido através do protocolo CTAB (Cetyl Trimetil Amônio Bromide) seguindo a rotina estabelecida por Doyle e Doyle (1990).

A qualidade e quantidade do DNA genômico foi avaliado através da técnica de eletroforese em malha de agarose $1 \%(\mathrm{~m} / \mathrm{v})$ mergulhado em tampão Tris, Borato, EDTA (TBE) $1 \mathrm{X}$ a 70 volts por 120 minutos. A geração das imagens resultantes da corrida foi realizada por meio do sistema de fotodocumentação Kodak, sob exposição à luz ultravioleta usando o intercalante GeIRed® (BIOTIUM) e a avaliação da concentração de DNA genômico foi realizada através da comparação de intensidade das amostras com o DNA do fago lambda (Lambda DNA/HindIII Marker).

Foram realizadas amplificações via PCR utilizando 23 sequências de primers ISSR, realizadas utilizando termociclador VeritiTM 96-Well Thermal Cycler (Applied Biosystems $^{\mathrm{TM}}$ ) em um volume total de $16 \mathrm{~L}$, correspondendo a $15 \mathrm{ng}$ de DNA genômico, tampão de amplificação 10X (20 mM Tris-HCl $[\mathrm{pH} 8,4]$ e $50 \mathrm{mM}$ de $\mathrm{KCl}$ ), 1,5 $\mathrm{mM} \mathrm{MgCl}_{2}, 0,2 \mathrm{mM}$ de cada desoxinucleotídeo trifosfato (dNTPs), 1 pM de primer e 1 de Taq DNA polimerase (Invitrogen, Carlsbad, Califórnia, EUA). A configuração 
dos ciclos de PCR foram: desnaturação inicial a $95^{\circ} \mathrm{C}$ por cinco minutos, 34 ciclos $\left(94^{\circ} \mathrm{C}\right.$ por 50 segundos, $48^{\circ} \mathrm{C}$ por 50 segundos e $72^{\circ} \mathrm{C}$ por um minuto), e extensão final a $72^{\circ} \mathrm{C}$ por cinco minutos, seguindo o protocolo sugerido por Santos et al. (2011).

Os amplicons foram corados com GeIRed® (BIOTIUM) e separados por corrida eletroforética em malha de agarose a $2 \%(\mathrm{~m} / \mathrm{v})$ mergulhado em tampão TBE $1 \mathrm{X}$ a 120 volts por 120 minutos. A geração das imagens resultantes da corrida foi realizada por meio de fotodocumentação, através da exposição à luz ultravioleta.

$\mathrm{Da}$ análise do gel foi construída uma base de dados binários sendo atribuído 0 para ausência, 1 para a presença de marcadores e 9 para dados inconclusivos. Os primers foram classificados através do padrão de geração de fragmentos observados, em (I) Bom - amplicons visíveis em todos os genótipos; (ii) Ruim amplicons em todos os genótipos com má qualidade de visualização, e; (iii) Ausente - ausência de amplicons visíveis.

A tabela de dados binários em Excel ${ }^{\circledR}$ serviu para o cálculo das frequências alélicas para a determinação do índice de heterozigosidade esperada $(\mathrm{He})$ e do Conteúdo de Informação Polimórfica (PIC, Polymorphism Information Content), avaliados com o software GENES (CRUZ, 2006). A He do locus foi calculada pela fórmula proposta por NEI (1973), onde é considerada que as populações estudadas estão em equilíbrio: $H_{\theta}=1-\sum_{i=1}^{k} x_{i}{ }^{2}$ Onde: $x_{i}=$ Frequência de alelo i, $\mathrm{k}=$ Número de alelos. O PIC quantifica a informação do locus marcador, calculado de acordo a seguinte fórmula: PIC $=1-\left[\sum_{i=1}^{k} x_{i}^{2}\right]-\sum_{i=1}^{k-1} \sum_{j=i+1}^{k} 2 x^{2} i 2 x^{2} j$ (BOLSTEIN et al., 1980).

\section{RESULTADOS E DISCUSSÃO}

O perfil de geração de marcas dos iniciadores foi classificado considerando a quantidade de geração de marcas das amostras avaliadas e a qualidade de visualização das mesmas, exemplificadas na Figura 1.

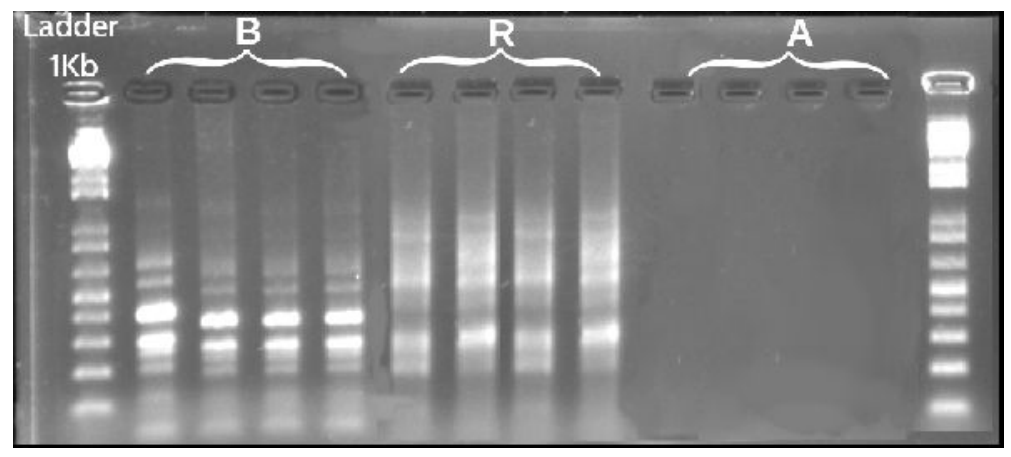

FIGURA 1. Ilustração da classificação de perfil de geração de fragmentos genômicos de Melocactus conoideus através da amplificação por primers ISSR. Classificados como: (B) Bom (R) Ruim e (A) ausente. Fonte: Autores.

Do total de 23 primers ISSR testados, $15(65,2 \%)$ apresentaram marcas nítidas e possibilitaram a realização da análise de polimorfismo (Tabela 1). Para estes iniciadores, foi observado 118 marcadores no total, com média de 7,87 marcadores por primer. A quantidade de marcações por primer variou de quatro 
(TriCAC3'RC) a 11 (TriCGA3'RC). Quarenta e oito marcadores foram polimórficos, sendo o primer DiGA3'T o que apresentou o maior número de marcadores polimórficos (8). Dois iniciadores (TriCAC3'RC e TriTGT3'YC) apresentaram apenas marcadores monomórficos.

TABELA 1. Perfil de segregação de fragmentos amplificados e polimorfismo para os 23 primers Inter Simple Sequence Repeat (ISSR) no acesso às regiões genômicas de Melocactus conoideus.

\begin{tabular}{|c|c|c|c|c|c|}
\hline $\begin{array}{l}\text { iciadores } \\
\text { Código }\end{array}$ & Sequ & $\mathbf{N}$ & MP & (\%) & PA \\
\hline $\mathrm{DiCA}^{\prime} \mathrm{G}$ & A) ${ }_{8} G$ & 7 & & 2,8 & \\
\hline DiCA & & & & 3,3 & \\
\hline DiCA & & & & & \\
\hline DiGs & & 10 & 3 & 3 & \\
\hline DiGAś & & & & & \\
\hline חin & & 0 & 8 & 80 & \\
\hline $\mathrm{RC}$ & & 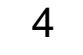 & 0 & & \\
\hline YC & & - & & & \\
\hline & & - & & & \\
\hline RC & & - & & & \\
\hline YC & & - & & & $\mathrm{h}$ \\
\hline YC & & 5 & 0 & & \\
\hline & & 0 & 7 & 77.7 & \\
\hline $\mathrm{RC}$ & & 10 & ? & 20 & \\
\hline $\mathrm{RC}$ & & 5 & 1 & 20 & \\
\hline$R C$ & & 7 & 2 & 85 & \\
\hline $\mathrm{RC}$ & & 7 & 2 & 28,5 & 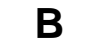 \\
\hline $\mathrm{RC}$ & C & 11 & 4 & 36,3 & \\
\hline $\mathrm{RC}$ & & 9 & 6 & 66,6 & \\
\hline $\mathrm{RC}$ & & - & - & & $n$ \\
\hline $\mathrm{RC}$ & & 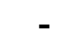 & - & - & 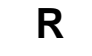 \\
\hline $\mathrm{RC}$ & C & 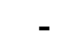 & - & 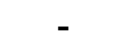 & 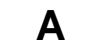 \\
\hline TriGGA3“RC & $(\mathrm{GGA})_{5} \mathrm{RC}$ & 8 & 3 & 37,5 & \\
\hline
\end{tabular}

Nota: $\boldsymbol{N}$ número de marcas, $\mathbf{M P}$ Marcas polimórficas, $\boldsymbol{P}(\%)$ Percentual de polimorfismo, $\boldsymbol{P A}$ Perfil de Amplificação, $\boldsymbol{B}$ Bom, $\boldsymbol{R}$ Ruim e, $\boldsymbol{A}$ Ausente.

Estudos prévios de caracterização de sequencias de primers ISSR realizados para diferentes espécies vegetais e animais apresentaram resultados variáveis no que diz respeito ao número de marcadores observados e polimorfismo. Neste sentido, análise em Croton linearifolius a partir dos mesmos primers utilizados neste estudo, permitiu a geração de 136 marcadores e 22,8\% de polimorfismo (SILVA, et al., 2018). Em Atta sexdens, dos 23 primers testados 12 foram considerados ideais para a espécie, apresentando 88 marcadores e $59 \%$ de polimorfismo (MATOSOLIVEIRA, et al., 2018). Em espécies do gênero Passiflora foram testados alguns 
dos primers usados neste estudo, mostrando um alto percentual de marcas polimórficas (SANTOS, et al., 2011).

Para a família Cactaceae, a análise de 17 sequencias de primers ISSR em Cereus sp. permitiu a geração de 180 marcadores e a seleção de 15 primers polimórficos (DOMINGUES et al., 2017). Esses dados mostram que um conjunto de primers ISSR evidenciam uma variedade de padrões de geração de marcas para diferentes organismos, o que implica na necessidade de análise prévia destes primers antes de começar o estudo para uma espécie. Para $M$. conoideus os 15 marcadores considerados como bons neste trabalho (Tabela 1) possuem potencial uso em estudos moleculares, mesmo aqueles considerados como monomórficos, já que estes podem evidenciar polimorfismos em número maior de genótipos analisados.

Os índices: conteúdo de informação de polimorfismo (PIC) e heterozigosidade esperada $(\mathrm{He})$ foram gerados para os primers que permitiram a genotipagem molecular. O PIC atingiu valores entre 0,29 e 0,37 , com valor médio de 0,33. A He exibiu valores entre 0,36 á 0,49, com média de 0,43 (Tabela 2). O PIC corresponde à eficiência do iniciador em detectar polimorfismo, valores acima de 0,5 indicam que o primer é altamente informativo, entre 0,25 e 0,5 moderadamente informativo e abaixo de 0,25 pouco informativo (BOLSTEIN et al., 1980). Nesse sentido, utilizando esse parâmetro, pode-se considerar que os primers usados neste estudo são moderadamente informativos para a análise genética de $M$. conoideus.

TABELA 2. Conteúdo de informação de polimorfismo (PIC) e Heterozigosidade esperada $(\mathrm{He})$ a partir de primers ISSR na análise em de Melocactus conoideus.

\begin{tabular}{|c|c|c|}
\hline Iniciadores & $\mathrm{He}$ & PIC \\
\hline DiCA3‘G & 0,40 & 0,31 \\
\hline DiCA3‘RG & 0,41 & 0,32 \\
\hline DiGA3‘C & 0,43 & 0,33 \\
\hline DiGA3‘ RC & 0,36 & 0,29 \\
\hline DiGA3‘ $T$ & 0,36 & 0,29 \\
\hline TriCAC3‘RC & 0,49 & 0,37 \\
\hline TriTGT3‘YC & 0,49 & 0,37 \\
\hline TriAAC3`RC & 0,41 & 0,32 \\
\hline TriAAG3‘RC & 0,44 & 0,34 \\
\hline TriACG3‘RC & 0,46 & 0,35 \\
\hline TriAGA3‘RC & 0,47 & 0,36 \\
\hline TriTGG3‘RC & 0,47 & 0,36 \\
\hline TriCGA3‘RC & 0,42 & 0,32 \\
\hline TriCGC3‘RC & 0,43 & 0,33 \\
\hline TriGGA3‘RC & 0,44 & 0,34 \\
\hline MÉDIA & 0,43 & 0,33 \\
\hline
\end{tabular}

A He é um índice de estimativa de variabilidade genética destinada para o estudo de genética de populações que utiliza as frequências de ocorrência de loci 
monomórficos e polimórficos dentro e entre populações para estimativa do grau de estruturação genética ocorrente (NEI, 1973). Neste estudo, esse parâmetro foi usado como forma de observar o quanto os primers ISSR acessam de variação dentro de uma amostra pequena de genótipos de $M$. conoideus.

Os primers ISSR demonstraram acessar uma diversidade genética relativamente alta para a espécie, considerando estudos de variabilidade genética para membros da família, tal como Ferocactus histrix com valores médios de $\mathrm{He}=$ 0.178 à 0.195 (CASTRO-FELIX et al., 2014). Contudo, na medida em que se aumenta o número de genótipos avaliados os valores tanto de He quanto de PIC podem sofrer variação.

Os primers ISSR têm sido aplicados em diferentes espécies de Cactaceae a fim de desvendar questões diversas a exemplo de estudos de variabilidade genética (CASTRO-FELIZ et al., 2014; GANOPOULOS, 2015), análises filogenéticas (REALINI et al., 2015) e identificação de variação somaclonal em raízes cultivadas in vitro (TORRES-SILVA et al., 2018). A maior parte destes trabalhos visa contribuir com informações que permitam auxiliar no manejo das espécies para sua conservação. Tendo em vista a baixa quantidade de informações moleculares em bancos de dados acerca de muitas espécies de Cactaceae, o uso de marcadores informativos e que não exigem informações prévias do genoma como os ISSR, configuram em excelentes meios de obter informação genético-molecular de forma segura, rápida e de relativo baixo custo.

Trabalhos de seleção de marcadores moleculares com o gênero Melocactus são escassos e estudos com ênfase aos efeitos da fragmentação ambiental sobre a diversidade genética de espécies da família das cactáceas com marcadores moleculares também, sobretudo com espécies endêmicas e dentro das categorias de ameaça da IUNC (CERQUEIRA-SILVA; SANTOS, 2008; ZAPPI et al., 2011; MACHADO et al., 2013). Portanto, a perspectiva desse estudo é servir como fonte de informação para análises moleculares futuras com a espécie, com vistas à compreensão de aspectos ecológicos que influenciam na reprodução, sobrevivência e diversidade da espécie, que consequentemente impactam na melhoria do manejo de $M$. conoideus, podendo servir de extensão para outras espécies do gênero.

\section{CONCLUSÃO}

Este trabalho representa os primeiros esforços para análise genéticomolecular em Melocactus conoideus. Os quinze marcadores ISSR aqui caracterizados com bom perfil de amplificação atestam a eficiência destes iniciadores em acessar regiões genômicas de $M$. conoideus e possuem potencial uso em diversas análises genéticas, devendo, portanto ser priorizados em futuros estudos. Neste contexto, os marcadores ISSR selecionados estão sendo empregados em análise de diversidade e estrutura genética de populações naturais de $M$. conoideus e os futuros resultados deverão auxiliar no manejo consciente visando à conservação da espécie.

\section{REFERÊNCIAS}

BOLSTEIN, D; WHITE, R.L; SKOLNICK, M; DAVIS, R.W. Construction of genetic linkage map in man using restriction fragment length polymorphism. American Journal of Human Genetics, v.32, p.314-331, 1980. Disponível em: < https://www.ncbi.nlm.nih.gov/pmc/articles/PMC1686077/pdf/ajhg00189-0020.pdf> 
CASTRO-FELIZ, P.; ROSAS-ESPINOSAS, V. C.; DÍAZ-CÁRDENAS, B.; PÉREZVALENCIA, L. I HUERTA-MATÍNEZ, F. M. et al. Genetic diversity within a declining natural population of Ferocactus histrix (DC) L indsay. Plant species biology, v. 29, n. 3, p. E21-E30, 2014. ISSN 0913-557X. DOI: <https://doi.org/10.1111/14421984.12028>.

CERQUEIRA-SILVA, C. B. M.; SANTOS, D. L. Estado da arte" do Melocactus conoideus: uma espécie endêmica ameaçada de extinção. Boletín de la Sociedad Latinoamericana y del Caribe de Cactáceas y otras Suculentas, v. 5, n.3, p. 1217, $2008 . \quad$ Disponível em:

http://www.ibiologia.unam.mx/slccs/www/pdf/Boletin/Vol_5_No_3_Sep

Dic_2008.pdf>

CORREIA, D.; DO NASCIMENTO, E. H. S.; GOMES FILHO, A. A. H.; LIMA, M.; DE ALMEIDA, J. V. F. Melocactus Embrapa Agroindústria Tropical-Documentos (INFOTECA-E), $2018 . \quad$ Disponível em:< https://www.infoteca.cnptia.embrapa.br/infoteca/bitstream/doc/1088141/1/DOC18001 .pdf>

COSTA, D. F.; VIEIRA, F. A.; FAJARDO, C. G.; CHAGAS, K. P. T. Diversidade genética e seleção de iniciadores ISSR em uma população natural de mangaba (Hancornia speciosa Gomes)(Apocynaceae). Revista Brasileira de Fruticultura, v. 37, n. 4, p. 970-976, 2015. Disponível em: <http://dx.doi.org/10.1590/0100-2945246/14>. doi: 10.1590/0100-2945-246/14

CRUZ, C. D. Programa Genes: estatística experimental e matrizes. Viçosa: Universidade Federal de Viçosa. 382 p. 2006.

DOMINGUES, S. D.; NEVES, A. F.; MANGOLIN, C. A. Seleção de primers para análise de Inter Simple Sequence Repeats (ISSR ) em Cereus sp . (Cactaceae ) Selection of primers for Inter Simple Sequence Repeats (ISSR) in Cereus sp (Cactaceae ). Revista Biotecnologia \& Ciência, v.6(ss), p. 46-54, 2017. Disponível em: < http://www.revista.ueg.br/index.php/biociencia/article/view/6799>

DOYLE, J.J.; DOYLE, J.L. Isolation of plant DNA from fresh tissue. Focus, Rockville, v.12, n.1, p.13-15, 1990.

FAJARDO, C. G.; VIEIRA, F. A.; \& MOLINA, W. F. Conservação Genética de Populações Naturais: Uma Revisão para Orchidaceae. Biota Amazônia, v. 6, n. 3, p. 108-118. 2016. DOI: <https://doi.org/10.18561/21795746/biotaamazonia.v6n3p108-118>

GANOPOULOS, I.; KALIVAS, A.; KAVROULAKIS, N.; XANTHOPOULOU, A.; MASTROGIANNI, A. et al. Genetic diversity of Barbary fig (Opuntia ficus-indica) collection in Greece with ISSR molecular markers. Plant Gene, v. 2, p. 29-33, 2015. ISSN 2352-4073. DOI: <10.1016/j.plgene.2015.04.001> 
LUZ-FREIRE, H. P.; TRINDADE, D. P. F. D.; SÁ-NETO, R. J. D; CORRÊA, M. M. Survival dynamics of Melocactus conoideus Buining \& Brederoo (Cactaceae), a threatened species endemic to northeastern Brazil. Acta Botanica Brasileira., Feira de Santana, v. 28, n. 2, p. 293-297, Jun. 2014 DOI:< 10.1590/S010233062014000200016>

MACHADO, M.; TAYLOR, N.P.; BRAUN, P. \& ZAPPI, D. Melocactus conoideus. The IUCN Red List of Threatened Species 2013: e.T40914A2943248, 2013. DOI: <http://dx.doi.org/10.2305/IUCN.UK.20131.RLTS.T40914A2943248.en>. Downloaded on 03 December 2018.

MATOS-OLIVEIRA, C. F.; DIAS, C. S.; SANTOS, E. S. L.; \& SILVA, C. B. M. C. Caracterização e seleção de marcadores ISSR para análise genético-populacional de Atta sexdens (Hymenoptera: Formicidae). Multi-Science Journal, v. 1, n. 9, p. 46 , 2018.

Disponível em:https://ifgoiano.edu.br/periodicos/index.php/multiscience/article/viewFile/353/460

$\mathrm{NEI}, \mathrm{M}$. Analysis of gene diversity in subdivided populations. Proceedings of the National Academy of Sciences, v.70, p.3321-3323, 1973. Disponível em:< https://www.ncbi.nlm.nih.gov/pmc/articles/PMC427228/pdf/pnas00139-0051.pdf>

PMVC- Prefeitura Municipal de Vitória da Conquista. 2016. Disponível em:<http://www.pmvc.ba.gov.br/herbario-municipal-produz-mais-de-3-mil-mudas-emquatro-meses/> Acesso em: 13 de novembro de 2018, 7:00.

PMVC- Prefeitura Municipal de Vitória da Conquista. 2017. Disponível em: $<$ http://www.pmvc.ba.gov.br/herbario-municipal-auxilia-no-reflorestamento-da-serrado-periperi/ > Acesso em: 13 de novembro de 2018, 7:00.

RIZZINI, C. T. Melocactus no Brasil. IBDF, Jardim Botânico, 1982.

REALINI, M. F.; GONZÁLEZ, G. E.; FONT, F.; PICCA, P. I.; POGGIO, L. et al. Phylogenetic relationships in Opuntia (Cactaceae, Opuntioideae) from southern South America. Plant systematics and evolution, v. 301, n. 4, p. 1123-1134, 2015. ISSN 0378-2697. DOI: <10.1007/s00606-014-1154-1>

REDDY, M. P.; SARLA, N.; SIDDIQ, E. A. Inter simple sequence repeat (ISSR) polymorphism and its application in plant breeding. Euphytica, v. 128, n. 1, p. 9-17, 2002. Disponível:<https://link.springer.com/article/10.1023/A:1020691618797>

SANTOS, L. F.; DE OLIVEIRA, E. J.; DOS SANTOS SILVA, A.; DE CARVALHO, F. M.; COSTA, J. L. et al. ISSR markers as a tool for the assessment of genetic diversity in Passiflora. Biochemical Genetics, v. 49, n. 7-8, p. 540-554, 2011. ISSN 0006-2928.

SILVA, T. S. S.; FREITAS, J. S.; SANTOS, E. S. L.; DOS SANTOS CARDOSO, T.; \& CERQUEIRA-SILVA, C. B. M. Caracterização e seleção de marcadores moleculares em Croton linearifolius Mull. Arg. como subsídio para estudos genéticos. Multi- 
Science Journal, v. 1, n. 10, p. 4-8, 2018. Disponível em:< https://www.ifgoiano.edu.br/periodicos/index.php/multiscience/article/view/354>

TAYLOR, N. P. The genus Melocactus (Cactaceae) in Central and South America. Bradleya, 9, 1-80, 1991. DOl:<10.25223/brad.n9.1991.a1>

TAYLOR, N. P. Plants in peril, 17 melocactus conoideus. Curtis's Botanical Magazine, v. 9, n. 3, p. 138-141, 1992. DOl:<10.1111/j.1467-8748.1992.tb00086.x>

TORRES-SILVA, G.; RESENDE, S.; LIMA-BRITO, A.; BEZERRA, H.; DE SANTANA, $\mathrm{J}$. et al. In vitro shoot production, morphological alterations and genetic instability of Melocactus glaucescens (Cactaceae), an endangered species endemic to eastern Brazil. South African journal of botany, v. 115, p. 100-107, 2018. ISSN 02546299. DOI:<10.1016/j.sajb.2018.01.001>

TURChETTO-ZOlet, A. C.; TURChetTO, C.; PASSAIA, G.; ZANELLA, C. M. Capítulo 1 Marcadores genéticos baseados em DNA. Marcadores Moleculares na Era Genômica: Metodologias e Aplicações, - Ribeirão Preto: Sociedade Brasileira de Genética, p. 12, 2017. Disponível em:< https://www.sbg.org.br/sites/default/files/e_book_marcadores_moleculares_sbg_201 7_final.pdf>

ZAPPI, D.; TAYLOR, N.; RIBEIRO-SILVA, S.; MACHADO, M.; MORAES, E. D. et al. Plano de ação nacional para a conservação das cactáceas. Brasília: Instituto Chico Mendes de Conservação da Biodiversidade, 2011. Disponível em:< http://www.icmbio.gov.br/portal/images/stories/docs-plano-de-

acao/pan_cactaceas/livro_cactaceas_web.pdf>

ZAPPI, D.; TAYLOR, N.; SANTOS, M. R.; LAROCCA, J. Cactaceae in Lista de Espécies da Flora do Brasil. Jardim Botânico do Rio de Janeiro, 2018. Disponível em: <http://floradobrasil.jbrj.gov.br/jabot/floradobrasil/FB1558> 